\title{
\#EdTechHub
}

Realising the potential of technology in education

\section{Pakistan Topic Brief: Providing Distance Learning to Hard-to-reach Children}

Imdad Baloch, Tom Kaye, Saalim Koomar, Chris McBurnie

EdTech Hub, https://edtechhub.org Helpdesk Request Response No. 17

2020-06-17

DOI: 10.5281/zenodo.3885606 


\section{About this document}

Recommended Imdad Baloch, Tom Kaye, Saalim Koomar, Chris McBurnie (2020). citation. Pakistan Topic Brief: Providing Distance Learning to Hard-to-reach Children in Urban Slums and Remote Areas. (EdTech Hub Helpdesk Response No 17) DOI: $10.5281 /$ zenodo.3885606. Available at https://docs.edtechhub.org/lib/9TKV7H6E. Available under Creative Commons Attribution 4.0 International, https://creativecommons.org/licenses/by/4.0/.

Licence. Creative Commons Attribution 4.0 International https://creativecommons.org/licenses/by/4.0/.

You - dear readers - are free to share (copy and redistribute the material in any medium or format) and adapt (remix, transform, and build upon the material) for any purpose, even commercially. You must give appropriate credit, provide a link to the license, and indicate if changes were made. You may do so in any reasonable manner, but not in any way that suggests the licensor endorses you or your use.

Identifiers. $\quad$ 2405685:9TKV7H6E;10.5281/zenodo.3885606.

Internal use. $\quad$ g/d/1 mIRnUhVO8GEp4NyOaa2UB_C1il_-4-i8W7d1-t2xGv0 Version 1

Reviewers: Björn Haßler, Caitlin Moss Coflan 


\section{Table of contents}

Table of contents

About the EdTech Hub Helpdesk

Purpose of this brief

Executive summary 5

1. Introduction

2. The Pakistan context

2.1. Education sector analysis

2.2. Pakistan's COVID-19 educational response plan

2.3. Options to support alternative education in Pakistan

3. Distance learning modalities

3.1. Television

3.2. Interactive radio instruction

3.3. Mobile phones

3.4. Online learning

4. Recommendations

5. References 


\section{About the EdTech Hub Helpdesk}

The Helpdesk is the Hub's rapid response service, available to DFID advisers and World Bank staff in 69 low- and lower-middle-income countries. It delivers just-in-time services to support education technology planning. We aim to respond to most requests in 1-12 business days. Given the rapid nature of requests, we aim to produce comprehensive and evidence-based quality outputs, while acknowledging that our work is by no means exhaustive. For more information, please visit https://edtechhub.org/helpdesk/.

\section{Purpose of this brief}

In May 2020, the UK Department for International Development (DFID) requested support from the EdTech Hub Helpdesk to identify EdTech interventions that could provide Pakistani students with educational continuity. Specifically, DFID were seeking examples of how different technologies have been used in South Asia and beyond to provide the most hard-to-reach students (defined, for the purpose of this brief, as those residing in rural areas and urban slums) with education. This brief has been developed in response to that request. It includes:

1. Overview of Pakistan's decentralized education system

2. Descriptions of four categories of distance learning interventions with examples sourced from South Asia and and other global contexts that can inform planning in Pakistan.

3. Recommendations for education programme designers in Pakistan to consider as they develop distance education programmes for the hardest-to-reach children. 


\section{Execulive summary}

The COVID-19 pandemic has resulted in mass school closures that have forced governments around the world to seek alternative ways of providing education to children unable to attend schools. In Pakistan, nearly 40 million primary and secondary students are no longer able to attend school, compounding the 22.8 million children who are already out of school. In response, both government and non-government agencies have been implementing initiatives to provide learners with educational continuity from home. The UK Department for International Development (DFID) has been assisting the Government of Pakistan by providing technical support and finance to support interventions that provide access to education.

In May 2020, DFID requested the EdTech Hub Helpdesk support DFID to identify EdTech interventions that could provide Pakistani students with educational continuity.

Specifically, DFID were seeking examples of how different technologies have been used in South Asia and beyond to provide the most hard-to-reach students (defined, for the purpose of this brief, as those residing in rural areas and urban slums) with education. This brief has been developed in response to that request.

The brief starts with a high-level review of Pakistan's decentralised education system. This analysis provides insights into the Pakistani operating environment, which in turn helped the Helpdesk team identify examples of EdTech interventions that align with the Pakistani context. This section highlighted important factors including the need to ensure that any short-term investments improve both access to, and the quality of, education in the medium- to long-term; that Pakistan has high pre-existing levels of access to devices such as television and mobile phones but only one quarter of the population can access the internet at home; and that Pakistan has started to invest in producing television and radio content for students, and expanding internet access.

The next section focuses on four types of EdTech interventions which are commonly used to support distance education: television, radio, mobile phones and online learning. The section provides an overview of each tool, highlights examples of these tools being used in both South Asia and beyond, and analyses how each of these tools may, or may not, be appropriate for use in Pakistan. The section includes references to more than a dozen tools from as close to Pakistan as India, Bangladesh and Nepal, and as far away as Sierra Leone, Kenya and Tanzania.

Using this analysis as a foundation, the final section highlights ten recommendations for education programme designers in Pakistan to consider as they develop distance education programmes for the hardest-to-reach children. Some recommendations are more general but are exceptionally important factors often overlooked by programme designers. Other recommendations are more specifically tailored to the Pakistan context.

The Helpdesk team advises that the recommendations are read in full (see section 4) to ensure important contextual information is understood. A summary of each recommendation follows: 
Recommendation 1: The first priority should be to ensure that hard-to-reach children in Pakistan can access printed learning materials from home. Programme designers often forget that low- and no-tech interventions such as printed materials provide a cost-effective and easy-to-access way of ensuring students have educational continuity.

Recommendation 2: Educational television, mobile phone-learning and online learning can all be leveraged to support distance learning in Pakistan. However, these should be used in combination to heighten the chance hard-to-reach children in Pakistan can access education through at least one of these modalities.

Recommendation 3: Television should be used to support learning outside of the classroom both during and after the current pandemic. The high rate of television ownership across Pakistan suggests that this modality can support students in remote areas and urban slums. Existing, localised content from Teleschool, Taleem Ghar and (where possible) Khul Ja Sim Sim or Sim Sim Hamara should be used.

Recommendation 4: Mobile phones should be used to support learning both in, and outside of, the classroom. In Pakistan, mobile phones represent a low-cost tool that children in urban slums, students in remote areas and out-of-school children can access. Teachers can use phone calls, SMS messaging and WhatsApp to help students build foundational skills and offer psycho-social support given the high rate of mobile ownership in Pakistan.

Recommendation 5: Interactive radio instruction should not be a priority in the immediate response. Interactive radio instruction broadcasts will have limited reach in Pakistan due to the low rates of radio ownership in rural and urban areas. While radio instruction should not be considered in the short term, it could be used to reach out-of-school children in the medium- to long-term.

Recommendation 6: Educational resources need to be adapted to the local context and the needs of marginalised students regardless of the mode of delivery. Content should reflect the language, culture and competencies of target groups.

Recommendation 7: Regardless of the modality adopted, programme designers should attempt to reuse and re-deploy content wherever possible. This may include replaying the same content on various occasions or using content designed for one modality on another. This creates economies of scale and helps students with access to different modalities to engage with content.

Recommendation 8: Adequate training and support materials should be made available to teachers and caregivers to ensure they can effectively play their role in delivering remote education services. A robust communication plan should be developed to ensure students, teachers and parents are aware of the tools at their disposal to support learning continuity.

Recommendation 9: The federal ministry and provincial departments of education should ensure that their COVID-19 education plans are aligned and well-coordinated to effectively reach the students most in need.

Recommendation 10: As with more general education programming, any interventions developed to support COVID-19 should include a robust and agile monitoring, evaluation and research system. 


\section{Introduction}

The COVID-19 pandemic has resulted in mass school closures across the world. It is expected that these closures will have long-term negative impacts on education, and broader development outcomes, in low- and -middle-income countries (LMICs) (UNESCO, et al., 2020). In the face of these closures, LMICs encounter many obstacles to effectively delivering alternative forms of education. Obstacles include limited experience in facing such challenges, limited digital and pedagogical capacity among teachers, and constraints in power and connectivity. Furthermore, inequalities in learning outcomes are expected to widen within LMICs due to the challenges of implementing alternative modes of education in remote, rural or marginalised communities. It is expected that the most marginalised children will face the most substantial negative impacts on their learning outcomes (Malik, 2020).

Educational technology (EdTech) has been identified as an intervention that can address the acute impact of school closures through its potential to provide distance education. In this light, the UK Department for International Development (DFID) Pakistan team requested the EdTech Hub to develop a topic brief highlighting EdTech tools that may be able to support distance learning in Pakistan. Specifically, the team requested that the brief explore tools that could be used to provide distance education to children in remote rural areas and urban slums.

In response to the request, the EdTech Hub team conducted an extensive but focused desk review. The review occurred in two phases. The first phase was a rapid review of Pakistan's education system with a particular focus on hard-to-reach children. This involved examining key data, analysing the policy environment and exploring the factors that were expected to facilitate or hinder the ability of EdTech to provide distance learning. The second phase involved collating examples of four types of technology interventions commonly used to support distance learning - television, interaction radio instruction, mobile phones and online learning - around the world. It is important to note that this section does not look at programmes focused on the use of laptops (e.g., Pakistan's laptop programme) as these are not accessible for hard-to-reach students. Two examples were selected for each technological modality one from the South Asia region and a second from outside the region. The team analysed various examples, including evaluation data and research studies, to identify which of these models were relevant to the Pakistani context.

This brief begins with an overview of the Pakistan education landscape. The second section of the brief explores how the four modalities can help provide alternative education to hard-to-reach learners in Pakistan. We believe that multimodal approaches offer the best means of providing distance education to heterogeneous, hard-to-reach groups (Kaye, Groeneveld, Coflan \& Haßler, 2020). With this in mind, this section highlights examples of tools that could be used in Pakistan to support a multimodal approach that reaches the most hard-to-reach learners. The third and final section synthesises the article's findings, presenting recommendations to inform Pakistan's COVID-19 education response. 


\section{The Pakistan context}

This section provides an overview of Pakistan's education system. This section uses data obtained from government websites and other seminal sources to provide general contextual information. An in-depth analysis of all elements of the system is beyond the scope of this document although further details on key topics (e.g., girls' education, refugees, etc.,) can be found amongst the sources cited in this section. The section also examines Pakistan's response to COVID-19 with a specific focus on the education sector before finishing with an analysis of elements of the system that could either facilitate or hinder distance-learning initiatives.

The analysis in this section guided the selection of examples of EdTech interventions that have been included in Section 3.

\subsection{Education sector analysis}

Pakistan has one of the largest and most complex education systems in the world. Approximately 41 million Pakistani students between ages 5 and 16 are currently enrolled in primary and secondary education. These education services are overseen by a combination of the Federal Ministry of Education and the provincial governments. Table 1 provides an overview of relevant education sector statistics.

Table 1. An overview of statistics relating to Pakistan's education sector (Source: Government of Pakistan, 2018; ASER Pakistan, 2019)1

\begin{tabular}{|l|l|}
\hline Area relating to the education sector & Statistic \\
\hline Number of children in urban areas enrolled in school & $14,975,711$ \\
\hline Number of children in rural areas enrolled in school & $25,709,408$ \\
\hline Total number of children enrolled in school & $40,685,119$ \\
\hline Male : female ratio of children enrolled in school & $56: 44$ \\
\hline \% of Grade 5 students who can read a simple story in Urdu & $59 \%$ \\
\hline \% of Grade 5 students who can read a simple story in English & $50 \%$ \\
\hline \% of Grade 5 students who can do 2-digit division & $57 \%$ \\
\hline
\end{tabular}

In addition to the 40 million children enrolled in school, UNICEF (2020) reports that 22.8 million Pakistani children are not currently enrolled in school. This is the second-highest number of out-of-school-children (OOSC) in the world. Of these 22.8 million children, 5.3

\footnotetext{
${ }^{1}$ Various sources were reviewed to source data to support the analysis in this section. These sources often presented figures that were not consistent with each other. Where possible, figures from official sources have been used.
} 
million are dropouts and 17.5 million children have never been to school (Government of Pakistan, 2018; Government of Pakistan, 2020). At the primary level, 32\% of girls are out of school while $21 \%$ of boys are out of school (Human Rights Watch, 2018).

In addition to the need to enhance access, the quality of education received by those children who attend school requires improvement. As evidenced in Table 1, education outcomes are low, with approximately half of students reaching basic levels of literacy by grade 5 (Government of Pakistan, 2018). Similarly, only just over half of students in grade 5 have obtained basic proficiency in mathematics (ibid.). This is due in part to the limited hours of education received by children who do attend school and a lack of quality teachers (Ahmad, et al., 2014; Asad, et al., 2020).

Recognising these challenges, Pakistan is prioritising improving both access to, and the quality of, national education services. To enhance access, Pakistan has prioritised policies and programmes aiming to provide free and compulsory education for children aged 5-16. To improve quality, the government has recently restructured national, pre-service teacher education programming, reformed the examination system and enhanced basic school facilities (Hina, 2017; Government of Sindh, 2019; Government of the Punjab, 2019). Despite these improvements, much work is required to continue to improve both access to and the quality of education. In particular, financing has been a challenge. Pasha (2018) notes that Pakistan has spent an average of $2.2 \%$ of GDP on education over the past five years, far lower than many regional neighbours such as Bhutan (6.6\%) and Nepal (5.2\%). Table 2 compares government spending on education as a percentage of GDP in the South Asia region.

Table 2. Government spending on education as a percentage of GDP in South Asia. (Source: World Bank).

\begin{tabular}{|l|l|l|}
\hline Country & Year & Spend as percentage of GDP \\
\hline Afghanistan & 2017 & $4.1 \%$ \\
\hline Bangladesh & 2018 & $2.0 \%$ \\
\hline Bhutan & 2018 & $6.6 \%$ \\
\hline India & 2013 & $3.8 \%$ \\
\hline Maldives & 2016 & $4.1 \%$ \\
\hline Nepal & 2018 & $5.2 \%$ \\
\hline Pakistan & 2017 & $2.9 \%$ \\
\hline Sri Lanka & 2018 & $2.1 \%$ \\
\hline South Asia & 2018 & $2.1 \%$ \\
\hline
\end{tabular}


One main challenge Pakistan's education sector must overcome is the disparity between different segments of the population. One example of this is the difference in life outcomes of citizens in urban and rural areas. While the majority of the population resides in rural areas, most indicators related to life outcomes significantly favour those in urban areas. Table 2 highlights a few of the inequalities that persist between rural and urban contexts.

Table 3. Comparison of key indicators - Urban vs rural (Source: Pasha, 2018)

\begin{tabular}{|l|l|l|}
\hline & Urban & Rural \\
\hline Population & $36 \%$ & $64 \%$ \\
\hline Literacy rate & $76 \%$ & $53 \%$ \\
\hline $\begin{array}{l}\text { \% of the population with } \\
\text { access to key services (e.g., } \\
\text { health, education, etc.) and } \\
\text { infrastructure }\end{array}$ & $74 \%$ & $18 \%$ \\
\hline Average yearly income & PKR 7,510 (US\$ 45.5) & PKR 4,654 (US\$ 28.2) \\
\hline
\end{tabular}

Pasha (2018) highlights that inequalities also prevail between slums and more developed parts of urban areas. For example, immunisation, family planning and clean water facilities are often not available to families in slums. People in the bottom quintile of per capita income in urban slums have $50 \%$ less access to immunisation facilities. School infrastructure is also poorly designed and there are inadequate numbers of teachers. These inequalities have proved to be a stumbling block for access, quality and equity in education. This disparity provided the catalyst for DFID Pakistan to focus on learners living in hard-to-reach areas of Pakistan (inclusive of rural areas and urban slums) in order to address the inequalities that prevail across the country.

\subsection{Pakistan's COVID-19 educational response plan}

In Pakistan, the first case of COVID-19 was reported in the last week of February 2020. The government closed all educational institutions on 13 March 2020 to ensure the wellbeing and safety of children, teachers and parents. With learning outcomes in Pakistan already the lowest in the region (Fasih, et al., 2019), the government quickly recognised that this closure had the potential to further negatively impact performance.

In an attempt to ensure some level of learning continuity, both the national and provincial governments began exploring how technology could support learning. On 13 April 2020, the Federal Ministry of Education collaborated with the Ministry of Information and Broadcasting to launch the Teleschool initiative. Run by Pakistan Television Corporation (a state-owned broadcasting organisation), educational programming is broadcast via a dedicated terrestrial television channel between 8 a.m. and 6 p.m. daily. In Punjab, the School Education Department is broadcasting the 
Taleem Ghar television programme. ${ }^{2}$ Taleem Ghar provides digital education content developed by the Punjab Curriculum and Textbook Board for grades K-12. Both initiatives have also been financially and technically supported by the World Bank, DFID and USAID. The Sindh Education and Literacy Department partnered with a local EdTech firm to deliver education online. Digital content has been made available on an e-learning app for primary grades in Mathematics, Science, Urdu and Sindhi languages. The use of educational television to support learning is explored further in subsection 3.1 of this piece

More recently, on 4 May 2020, the Federal Ministry of Education released the National Education COVID-19 Response and Resilience Plan (K-12). The plan provides a framework of strategies and interventions for Pakistan's education system to cope with the effects of COVID-19 (Ministry of Education and Federal Training, 2020). The framework aims to ensure continuity of learning for all children and to support the provinces to achieve the development goals outlined in their respective education sector plans. The framework identifies a range of technology-based education interventions to support learners when schools are closed and after schools reopen. For example, the content must be developed for multiple grades and subjects and made available on different modalities and platforms (television, radio, web-based - blogs, video sites, applications accessible through smartphones, etc.,). The framework also sets a policy action to develop, implement and expand remedial / catch-up / Alternative Learning Pathways / Non-Formal Education (NFE) programmes for children who fall behind due to being out of school.

\subsection{Options to support alternative education in Pakistan}

The most effective COVID-19 education strategies leverage multiple modalities to ensure ongoing service provision (Haßler, et al., 2020). Multimodal education approaches can widen access to learning opportunities, especially among marginalised communities. Well-designed distance-learning strategies identify very specific student population segments by the modality type available to them (e.g., students in remote areas who only have access to phones, students in urban centres who have access to the internet, phones and radio). Strategies are then developed to provide responses that meet the specific needs of each group.

In Pakistan, education providers can use multiple modalities to support distance education delivery. As highlighted in Figure 1, more than 70\% of Pakistan's population can access television and mobile phone services. Additionally, $56 \%$ of the population has access to a smartphone while $25 \%$ of the population has an internet connection. Households in urban areas have greater access to each of these modalities than those in rural areas. Notably, over $60 \%$ of rural households have access to television and mobile phones. This would suggest that interventions leveraging technologies based on this existing coverage may have greater potential to achieve a positive impact.

\footnotetext{
${ }^{2}$ For more information on the Taleem Ghar initiative see Government of the Punjab (2020). This information is also available at https://taleemghar.punjab.gov.pk/.
} 


\section{ICT-HOUSEHOLD DATA}

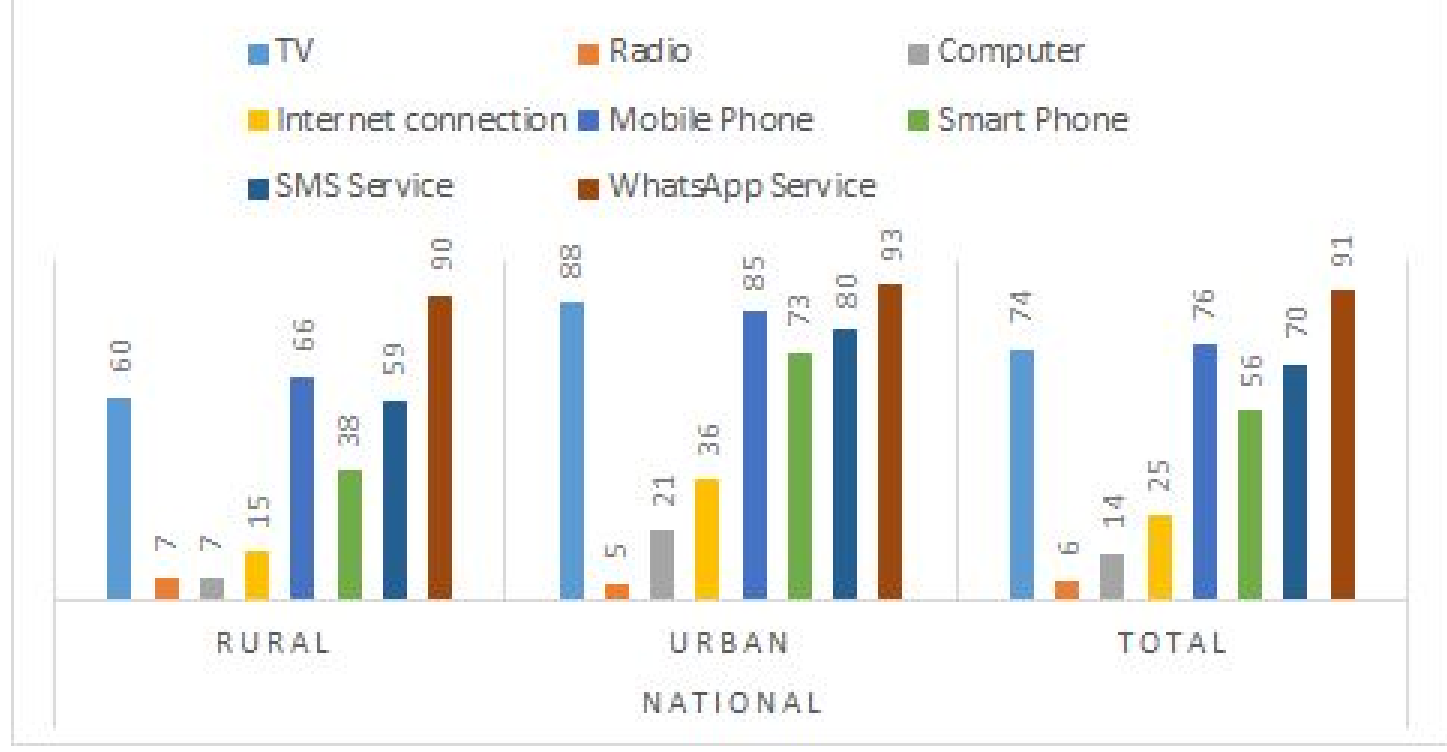

It is important to note that these national averages hide some significant disparities. In Punjab, for example, approximately $95 \%$ of the wealthiest quintile of households have access to television. This contrasts with the poorest quintile, where only $17 \%$ of households have access to television (Malik, 2020). While these national averages can provide a guide to alternative education options, the design of any programme will need to be based on data that highlights local contextual factors. All Pakistani provinces have high-functioning EMIS systems that can be leveraged to help appropriately target responses (Malik, 2020).

The Government of Pakistan is currently prioritising the development of the country's digital infrastructure. In 2018, Pakistan announced its first national digital policy known as 'Digital Pakistan'. The policy aims to utilise technology to enhance the outreach and quality of education, at all levels, across the country. The government appointed a special assistant to the Prime Minister to explicitly support this initiative. In the last four years, Pakistan has made considerable progress in the ICT sector. For example, computer labs have been built in almost all high schools. Despite this progress, there is still much improvement required. A study on the impact of computer labs in Punjab discovered that "only IT teachers used computers during their teaching" (Qadir and Hameed, 2018).

This topic brief reveals that Pakistan's education sector faces complex challenges ranging from inadequate infrastructure, limited financial resources, poor governance, and a lack of qualified human resources. However, the evidence discussed above also shows that the government of Pakistan is committed to ensuring quality education for all children. In this regard, Pakistan's COVID-19 education response is a reassuring manifestation of the government of Pakistan's approach towards education. The plan

\footnotetext{
${ }^{3}$ The statistics in this table come from the Pakistan Telecommunications Authority (2019a), the Pakistan Telecommunications Authority (2019b) and Miller et al. (2015).
} 
has explored different options and platforms to ensure that children can learn during school closures. The sections below have taken these challenges and opportunities into account to identify and propose the EdTech tools that could increase access to quality educational resources and opportunities at scale. 


\section{Distance learning modalities}

This section explores four EdTech modalities that can be used to support alternative education - television, radio, mobile phones and online learning. These modalities have been selected to highlight the different EdTech tools that Pakistan can harness to deliver remote learning opportunities to students in hard-to-reach areas.

At the request of the DFID Pakistan team, this section provides examples of how EdTech has been used to support distance education in LMICs both inside and outside of South Asia. Each subsection contains one example from South Asia and one from outside South Asia. Examples were selected according to the following criteria:

- The implementation country is an LMIC;

- The tool has been Implemented at scale (i.e., more than 1,000 users);

- The tool focused on addressing educational challenges relevant to the Pakistan context.

In examining the four modalities the section highlights elements of the examples that are of particular relevance to the Pakistan context. The findings of this section are then used as the foundation for the recommendations presented in Section 4 of this report.

\subsection{Television}

This subsection examines how television can be used to provide education services to hard-to-reach children in Pakistan. The subsection first provides a general overview of how television has been used to support distance education. It then focuses on examples from Bangladesh and Tanzania, before providing suggestions about how television can also be used as part of Pakistan's COVID-19 education response.

\subsubsection{Using television to support learning}

Television can be used as a tool to support learning both inside and outside the classroom, and in both formal and non-formal settings. Publicly broadcasted educational television tends to target early years and primary-level learners. Examples of this include shows like Sesame Street, a US children's television show which now reaches children in more than 150 countries. Television instruction can also target older learners through secondary school and university. Telesecundaria, an initiative that was started in Mexico more than 50 years ago, offers one example. Telesecundaria serves secondary school students in rural areas without access to local schools (USAID, 2020).

In response to the COVID-19 pandemic and the related mass school closures, countries such as China, Malaysia and Mongolia have begun to broadcast educational television programming (Basic Education Coalition, 2020; CGTN, 2020; Munkhzul, 2020). While formal evaluations of programme effectiveness are not yet available, evidence suggests televised educational content enhances learning more than if there were no learning resources present in households (USAID, 2020). In short, it is accepted that televised educational content can go some way towards providing educational continuity for students impacted by the COVID-19 crisis. 
The Kheda Communication Project (1975-1990) aimed to expose oppression in the contemporary social and economic system, mobilise communities to fight injustice and promote self-reliance amongst individuals and communities. ${ }^{4}$ It provided 650 television sets to 400 villages and organised participatory programme-making to produce shows of interest to multiple age groups. Though dated, this exemplifies the potential for televised programming to address equity issues. Participatory programming which involves the voices of hard-to-reach students can go some way to enhancing engagement from these particular groups.

While there is little research examining the impact of this initiative, this example demonstrates that historically this has been a tool used in South Asia. It shows that this style of programming can occur at scale and be implemented over the long-term.

\subsubsection{The use of television to support learning in Bangladesh}

The adaptation of Sesame Street beyond the show's original context includes Sisimpur, the Bangladeshi variant. ${ }^{5}$ Launched in 2005 , Sisimpur delivers education to young learners, both inside and outside the classroom. It reaches around two-thirds of preschool-aged Bangladeshi children who do not attend a formal school.

Sisimpur focuses on a broad range of subject matter, including literacy, numeracy and socio-emotional skills. Sisimpur also provides wider lessons on health and hygiene, disaster preparedness and financial empowerment. This context-specific, age-appropriate content promotes children's engagement in learning. A large-scale longitudinal study revealed that children who had regular exposure to Sisimpur demonstrated literacy, mathematics, and socio-cultural skills equivalent to children a year older (Lee, 2009). Furthermore, a BBC World Trust study in 2010 showed that Sisimpur was the most-watched children's programme on the state-owned network Bangladesh Television (Sesame Workshop, 2020). When segmenting viewers by location, Mares \& Pan (2013) found that $83 \%$ of children in urban locations and $58 \%$ of children in rural locations watched Sisimpur.

Sisimpur's reach has also been expanded to support the millions of Bangladeshi children who don't have access to a television. Additional interventions have included providing training to childcare centres and bringing Sisimpur to remote areas with mobile screenings on vans and rickshaws (Sesame Workshop, 2020). These initiatives are promising as Sisimpur represents educational programming that is localised and prevalent throughout Bangladesh. The learnings taken from ongoing initiatives to expand the programme's reach will be of value to those for hard-to-reach populations of Pakistan. As initiatives to expand Sisimpur's reach are in their infancy, there is no readily available data on their impact. However, Sisimpur exemplifies the potential of

\footnotetext{
${ }^{4}$ Information on the Kheda Communication Project is available at http://ecoursesonline.iasri.res.in/mod/page/view.php?id=116100.

${ }^{5}$ For more information on Sisimpur see Sesame Workshop (2020). This information is available at https://www.sesameworkshop.org/what-we-do/shows/sisimpur.
} 
localised educational television programming that is culturally-sensitive, age-appropriate and scalable.

Almost two decades ago, Pakistan Television, with support from Active Learning Initiative Family (ALIF) broadcasted Khul Ja Sim Sim - an Urdu version of Sesame Street (Iqbal, 2020). In response to parents' and children's demand, a modernised version of the same programme was re-broadcasted by Pakistan's state-owned Pakistan Television in 2009 with the support of the Pakistan Educational Network (Mohiuddin, 2009). Following this, USAID launched a project to support the adaptation of Sesame Street, called Sim Sim Hamara. However, the project was terminated by USAID in 2012. The withdrawal of funds by USAID supporting the adaptation of Sim Sim Hamara (the Pakistani adaptation of Sesame Street) in 2012 due to allegations of corruption may present barriers to future roll-outs in Pakistan (BBC, 2012; Boone, 2012; Bricklin, 2012). However, the fact that there is existing content, and that characters and stories have already been developed, presents an opportunity to scale this programming at pace. Furthermore, the low cost of the programme - reported to be around 16 cents per person based on estimates from the Indian adaptation Galli Galli Sim Sim - means that this initiative has the potential to be quickly scaled at an affordable cost (Batada et al., 2016). Whether or not the programme's history presents a barrier too large to overcome, the evidence supports the production of context-specific programming to promote distance learning. Additionally, this style of educational television can provide benefits to both children who have previously attended school and those who have not previously enrolled.

\subsubsection{The use of television to support learning in Tanzania and other LMICs}

Ubongo Kids, run by the NGO Ubongo, has reached more than 17 million viewers in 31 countries through its "edutainment" programming (Ubongo, 2020). As with Sisimpur, Ubongo Kids delivers programming on core subjects such as mathematics and science as well as broader issues including gender rights and financial literacy. Ubongo Kids is offered through multiple modalities with radio, app-based and paper-based materials supporting the televised content, enabling the programme's rapid expansion. A recent national survey of Tanzanian children reported that 1 in 6 children had viewed the locally produced educational television programme (Watson, 2020). The prevalence of Swahili speakers has contributed to the programme's expansion, as ease of adaptation has allowed intra-regional scaling. In addition to Swahili, Ubongo Kids has also been translated into five other languages.

Ubongo has managed to assess its impact through mobile surveys, control trials and audience tracking. Impact data from a 2016 trial suggests that children who watched Akili and Me (the Rwandan adaptation of Ubongo Kids) had significantly higher scores for counting, number recognition, shape knowledge, letter identification, colour identification, body-part recognition, health knowledge and vocabulary, relative to a comparison group (Borzekowski, et al., 2019). Thus, Ubongo Kids had a positive impact on learning in this context.

Ubongo Kids plans to make toolkits available to caregivers and practitioners working in early childhood development to support home-based learning during mass school closures. The transfer of educational responsibility from schools to households means 
such toolkits can help support caregivers to facilitate a productive learning environment. While evidence of the programme's ability to support the hardest to reach is scarce, leveraging this type of intervention as part of a multimodal-delivery approach may help overcome issues of equity. Ubongo has worked to develop a multimodal approach with resources also developed for radio, mobile use and print to reach 'rural, non-electrified communities' (Ubongo, 2020).

In addition to its scale, influence on learning outcomes and cross-country adaptation, Ubongo Kids is cost-effective. Experience broadcasting Ubongo Kids in Tanzania suggests per-person, per-year costs are approximately one cent. However, these figures are based solely on developing the content, with costs affiliated with purchasing technology, power or connectivity not included in this estimate ( Watson, 2020).

\subsubsection{The potential use of television as part of Pakistan's COVID-19 education response}

Existing television ownership in LMICs is significant (Fernald, et al., 2011). Figure 1 (above) demonstrates that Pakistan is no exception, with national television ownership at $74 \%$, and $60 \%$ in rural areas. Thus, educational television programmes could be a viable means of maintaining education provision during COVID-19-related school closures. However, targeting hard-to-reach Pakistani children in remote areas and urban slums requires addressing equity issues. If approximately $40 \%$ of students in rural areas cannot access television, existing intra-country inequalities could potentially be exacerbated. Hence, while educational television content can support distance learning in Pakistan, the way in which it is deployed must be targeted to the most marginalised to ensure programmes do not exacerbate existing inequalities.

Both Sisimpur and Ubongo Kids demonstrate the potential effectiveness of educational television in LMIC contexts. Both examples reinforce that adapting content to ensure it is linguistically and culturally appropriate is an important step in ensuring a positive impact on learning outcomes. Though broader questions of equity remain, both examples offer tentative approaches to overcome these issues. Sisimpur has offered mobile screenings using readily-available transportation while Ubongo Kids has the scope to deliver content offline and through radio and mobile transmission. As such, the producers of both these examples of educational programmes have acknowledged the need to do more to make programming available to those who are hardest to reach.

The evidence from Sisimpur and Ubongo Kids suggests that educational television is a viable option for policymakers seeking to improve core learning and socio-emotional outcomes at scale in a cost-effective manner. Educational programmes can be developed into multifaceted tools inclusive of health information, awareness around disabilities, positive gender norms and more. The use of characters with disabilities, for example, can raise awareness and support children to accept differences (Watson, 2020).

However, there are limited means to track if and how much children learn from educational television programming. While it may be possible to gauge viewership, monitoring progress in learning would require additional resources, such as online or SMS-based apps to administer quizzes. Again, issues of equity also arise in relation to 
the tools used (such as a smartphone-based app or online platform) to conduct such monitoring and evaluation.

While using existing international programming is cost-effective, evidence suggests that televised educational content better promotes learner engagement when it is adapted to be context-specific. With a base of localised content already in place, Pakistan-specific adaptation of educational television content is recommended. Teleschool at the national level and Taleem Ghar in Punjab, both referenced above, are examples of programmes that could be rolled out more widely. These programmes have the potential to reach nearly two-thirds of all children in Pakistan. Options to rebroadcast Khul Ja Sim Sim or Sim Sim Hamara should be explored, given the successful track record of adaptations of Sesame Street globally.

Television instruction can offer a way of reaching a large number of learners while also turning a passive learning experience into an active one. However, while this modality can reach many users, and has been shown to improve learning outcomes if contextually appropriate, issues related to ensuring equity persist. To begin addressing these remaining challenges, it would be prudent to pair television programming with printed materials, mobile phone-based resources and online learning to increase the opportunities for hard-to-reach children to access learning materials.

\subsection{Interactive radio instruction}

This subsection examines how interactive radio instruction can be used to provide education services to hard-to-reach children in Pakistan. The subsection first provides an overview of how interactive radio instruction can be used to support distance education generally. It then focuses on case studies in India and West Africa before providing suggestions on how interactive radio instruction can be used to support Pakistan's COVID-19 education response.

\subsubsection{Using interactive radio instruction to support learning}

Educators can use interactive radio instruction to broadcast learner-centred, interactive educational content via the radio. Interactive radio instruction combines the use of radio broadcasting with materials that are used during or following the broadcast. Education providers have conventionally used interactive radio instruction to support teachers to structure and facilitate active learning in the classroom. In recent years, however, educators have turned to interactive radio instruction to deliver education to out-of-school children and to ensure continuity of learning during health crises (USAID, 2020).

Box 2. What does an interactive radio instruction lesson look like?

A typical 30-minute interactive radio instruction broadcast will follow a three-part structure. First, a radio teacher will explain a concept to listeners. Afterwards, radio actors will model and practically apply these ideas. The teacher will then suggest exercises for students to complete at home. Typical activities include quizzes, singing, 
role-play and storytelling. During lessons, parents and caregivers will receive instructions on how to support children with unfamiliar content.

Education system leaders need to invest time and money to design curriculum-aligned materials that reflect the context in which students learn. Before launching an interactive radio instruction programme, governments need to identify aspects of the curriculum that have the biggest impact on a student's academic progress (Mundy \& Hares, 2020). Education providers could, for instance, focus on primary-level numeracy. Previously, interactive radio instruction programmes have improved learning outcomes in mathematics, literacy and social studies (Ho \& Thukral, 2009).

Education providers can adapt and re-record scripts from other countries to align with national curricular standards and local cultural traits (World Bank, 2005; Richmond, 2020). In doing so, educators can reduce the time and cost of developing and testing content for a radio-based education response to COVID-19.

The impact of interactive radio instruction remains unclear outside of a classroom context. Recent research has shown that although radio-based education may not compensate for a loss of schooling, interactive radio instruction can help children maintain a link to learning (Hallgarten, 2020; McAleavy \& Gorgen, 2020). Education providers need to, however, recognise that many households may not have access to radio broadcasts. In Pakistan, for instance, only 5\% of urban households and $7 \%$ of rural households own a radio (National Institute of Population Studies, 2019). Meanwhile, evidence from the Ebola epidemic suggests that most students require the support of a caregiver or study group to benefit from broadcasts (Plan International, 2015).

While these limitations do not necessarily preclude the possibility of a successful interactive radio instruction programme in Pakistan, education providers need to carefully consider these issues. Programmes leveraging interactive radio instruction may need to consider the procurement of radios or other devices (e.g., MP3 players) that can be used to provide audio instruction.

\subsubsection{The use of interactive radio instruction to teach hard-to-reach and out-of-school-children in India}

The Technology Tools for Teaching and Training (T4) programme in India aimed to improve learning outcomes among marginalised students between 2002 and $2011 .{ }^{6}$ The programme focused on girls, children in rural areas and students of a low caste. A key component of this initiative included interactive radio instruction for learners both in and out of schools.

The T4 programme initially used interactive radio instruction to help students develop their English language skills. In subsequent years, the initiative expanded to a multimodal approach where interactive radio instruction, educational television and computer-based audio content were used to teach English, mathematics and science. The programme reached more than $\mathbf{4 0}$ million students across eight states.

\footnotetext{
${ }^{6}$ Here we draw on Carlson's (2013) detailed overview of the T4 programme.
} 
The T4 initiative adopted an iterative approach to programme design. User researchers consulted parents, students and teachers to monitor the extent to which audio lessons met the needs of learners. This information underpinned a five-step process that involved design, revision, testing, refinement and delivery.

Box 3. The impact of the Technology tools for Teaching and Training interactive radio instruction programme (Source: Carlson, 2013)

A study of 34,000 participants in Chhattisgarh found that the intervention resulted in statistically significant improvements in learning outcomes across all three subject areas. In 2008, for example, Grade 4-students increased their mathematics scores by an average of 29 percentage points. The study also found that boys and girls benefited equally from the initiative. In other words, the T4 programme did not exacerbate existing gender divisions.

USAID worked with eight Indian states and a range of local and international partners to co-finance this project. An impact evaluation report noted that the programme's five-year second phase cost $\$ 14.4$ million. In this period, the initiative reached a total of 85 million students. Based on these estimates, the programme had an annual per-student cost of $\$ 0.03$.

\subsubsection{The use of interactive radio instruction to ensure continued learning in West Africa during the COVID-19 pandemic}

Prior to the COVID-19 pandemic, Rising Academies ran a network of 160 schools that served 50,000 students in Liberia and Sierra Leone. In March 2020, Rising Academies partnered with the governments in these two countries to create an interactive radio instruction programme for out-of-school learners. This programme specifically targets students in remote rural areas who cannot access the internet. The current initiative is estimated to reach 1.4 million children in Liberia and Sierra Leone.

Within two weeks of school closures, Rising Academies started to air radio lessons that covered foundational numeracy and literacy skills. In Sierra Leone, radio stations charge Rising Academies $\$ 30-60$ for a one-hour slot. Meanwhile, Rising Academies pays a private studio $\$ 30$ to record a single interactive radio instruction lesson.

Rising Academies is currently developing the capacity to use text messages and WhatsApp to share audio recordings with learners who cannot access national radio. In doing so, Rising Academies aims to ensure that remote communities can access educational content.

Rising Academies has also developed a web portal where international partners can download freely available, standardised scripts for interactive radio instruction lessons. Partners can adapt, record and deliver this content to students in their own countries. These scripts cover literacy and numeracy at five levels from early childhood education to senior secondary school. Rising Academies has incorporated important safeguarding messages into their content. In the past three months, 25 education providers from 16 countries have used these resources. In Pakistan, for example, Innovate Educate Inspire 
(IEI) has translated content from the web portal into Urdu for delivery on MP3 players. ${ }^{7}$ IEI aims to ensure that children in remote areas of Gilgit-Baltistan have access to learning continuity.

Similarly to the T4 project, Rising Academies has adopted an iterative approach to programme design. At the end of each radio lesson, Rising Academies encourages parents and students to give feedback via SMS and a telephone hotline. Meanwhile, teachers from the Rising Academy school network regularly call their students to see what they think of radio lessons.

While the impact of this programme is not known, the Centre for Global Development is running a randomised control trial to evaluate the initiative. In the meantime, radio scripts and sample audio content can be found on the 'Rising on Air' web portal. ${ }^{8}$

\subsubsection{The potential use of interactive radio instruction as part of Pakistan's COVID-19 education response}

The above examples indicate that governments and schools can use interactive radio instruction to support marginalised learners at a national scale. Marginalised learners could include children in urban slums, students in rural areas and those out of school.

Box 4. The potential cost-effectiveness of interactive radio instruction in Pakistan

The T4 programme in India suggests that interactive radio instruction can represent a cost-effective medium to improve student-learning outcomes. Initial price estimates indicate that interactive radio instruction broadcasts could represent a low-cost intervention in Pakistan. In Gilgit-Baltistan, for example, the state radio station charges $\$ 24.50$ (4,000 PKR) for a 20-minute slot. ${ }^{9}$ However, education providers should investigate the start-up costs of radio-based programming as these can be prohibitive in some areas. Moreover, it remains unclear if an interactive radio instruction programme for children who are confined to the home can achieve the same results as the T4 initiative.

Meanwhile, the 'Rising on Air' programme shows how interactive radio instruction can ensure out-of-school children have an opportunity to continue learning during and after the current crisis. The initiative also exemplifies how educators can re-record and adapt radio scripts. In Pakistan, national education providers could explore the possibility of broadcasting a tailored version of the 'Rising on Air' programme. Alternatively, education providers could look to work with small-scale organisations such as IEI who have already adapted content to the national context.

The case studies also demonstrate that interactive radio instruction programmes can deliver educational content over a number of years or the relatively short period that schools are closed. Accordingly, an investment in interactive radio instruction could

\footnotetext{
${ }^{7}$ Information on Innovate Educate Inspire Pakistan's response to COVID-19 is available at https://ieipakistan.org/openings/.

${ }^{8}$ The 'Rising on Air' web portal is available at http://www.risingacademies.com/on-air.

${ }^{9}$ These estimates reflect quotes that the state radio station in Gilgit-Baltistan provided to Innovate Educate Inspire in March 2020.
} 
support continuity of learning during the current pandemic as well as remedial education and for out-of-school children in the future. The experience of Rising Academies suggests that education providers can develop their first radio content in a couple of weeks. In Pakistan, Innovate Educate Inspire edited and translated a standardised script from the 'Rising on Air' programme in 2 days (Lamba \& Reimers, 2020).

Negotiations with radio stations can, however, prove a more significant challenge. In Gilgit-Baltistan, for instance, Innovate Educate Inspire decided to distribute audio content on MP3 players after a series of slow negotiations with the state radio station. This obstacle may be greater when education providers need to partner with multiple radio stations at a national level. In this situation, educators should adopt an incremental strategy that prioritises radio stations which reach the widest number of marginalised learners.

The impact of interactive radio instruction programmes depends in part on the number of learners who can access a radio. In Pakistan, only $5 \%$ of rural households and $7 \%$ of urban households own a radio (see Figure 1). Based on these estimates, radio-based interventions may have a limited capacity to reach a large number of students.

At the same time, radio broadcasts are being increasingly accessed on basic feature phones and smartphones (USAID, 2020). The relatively high level of mobile-phone ownership in Pakistan (see Figure 1) suggests that students may be able to listen to interactive radio instruction broadcasts without a conventional radio. This option may work best for learners in urban areas where the rate of mobile-phone ownership is highest. If education providers pursue this option, they should provide families with clear guidance on how to access interactive radio instruction content on their phones.

The widespread availability of mobile phones presents an opportunity to deliver content from interactive radio instruction lessons to children who live in remote areas that do not receive radio coverage. Similarly to Rising Academies, education providers could share audio recordings with learners via SMS or WhatsApp. In practice, education providers would require a current list of registered students to contact. Accordingly, this approach may have a negligible impact on the education of children who are unregistered and out of school.

\subsection{Mobile phones}

This subsection examines how mobile phones can be used to provide education services to hard-to-reach children in Pakistan. The subsection first provides an overview of how mobile phones are used to support distance education generally. Whereas other sections of this brief have provided two in-depth examples, this section highlights various ways that mobile phones have been used both before and during the COVID-19 crisis. The section then outlines how mobile phones can be deployed in Pakistan's COVID-19 education response. 


\subsubsection{Using mobile phones to support learning}

As of 2020, more than two-thirds of the world's citizens own a mobile phone (Turner, 2020). This has led educators and entrepreneurs to increasingly explore how these devices can support education provision.

There are three main types of mobile phone, each of which can be used to support distance education:

- Basic phones: Basic phones are not internet-enabled. While some basic phones may come with some simple apps, these phones are primarily used to make and receive calls and to send SMS messages.

- Feature phones: Feature phones generally retain the same form of a basic phone, but are also able to connect to the internet. While the internet is accessible, it is mainly used for web browsing and email. Additional applications may be available, but these are fixed during manufacturing.

- Smartphones: Like feature phones, smartphones allow users to make and receive calls, send SMS messages, and use the internet. Unlike feature phones, however, smartphones allow users to install applications above and beyond the original user interface. Smartphones are more powerful, meaning they can support more sophisticated applications than feature phones, process functions at a faster rate, and have additional functionality (e.g., cameras, etc.,)

Each phone type can be used to support education service delivery in several ways. These are outlined in Table 4.

Table 4. Distance learning modalities and technologies ${ }^{10}$

\begin{tabular}{|c|c|c|}
\hline Modality & Technology & Educational use \\
\hline $\begin{array}{l}\text { SMS and phone } \\
\text { calls }\end{array}$ & $\begin{array}{l}\text { - Basic phones } \\
\text { - } \text { Feature phones } \\
\text { - Smartphones }\end{array}$ & $\begin{array}{l}\text { - Broadcast messaging on important } \\
\text { updates } \\
\text { - SMS-based education services } \\
\text { - Small group classes convened over } \\
\text { - } \quad \text { Call centres staffed by teachers }\end{array}$ \\
\hline $\begin{array}{l}\text { Pre-recorded } \\
\text { Audio }\end{array}$ & $\begin{array}{l}\text { - Feature phones } \\
\text { - Smartphones / } \\
\text { Tablets }\end{array}$ & $\begin{array}{l}\text { - Interactive audio / radio instruction } \\
\text { programmes } \\
\text { - Audiobooks, podcasts, radio } \\
\text { dramas, two-way programmes }\end{array}$ \\
\hline $\begin{array}{l}\text { Pre-recorded } \\
\text { Video }\end{array}$ & $\begin{array}{l}\text { - Feature phones } \\
\text { - Smartphones / } \\
\text { Tablets }\end{array}$ & $\begin{array}{l}\text { - Video instruction programming } \\
\text { - Educational television broadcasting }\end{array}$ \\
\hline $\begin{array}{l}\text { Web-enabled } \\
\text { mobile learning }\end{array}$ & $\begin{array}{ll}\text { - } & \text { Feature phones } \\
\text { (internet-enabled) } \\
\text { - Smartphones }\end{array}$ & $\begin{array}{l}\text { - Electronic teaching and learning } \\
\text { materials (e.g., learning packs, } \\
\text { M-novels, mobile storybooks) } \\
\text { - Use of Open Educational Resources }\end{array}$ \\
\hline
\end{tabular}

${ }^{10}$ This table was adapted from Adam et al. (2020) 


\begin{tabular}{|c|c|c|}
\hline & & $\begin{array}{l}\text { Virtual web-based teaching and } \\
\text { learning groups } \\
\text { - Web-based mobile-compatible } \\
\text { Learning Management Systems } \\
\text { (LMS) and Massive Open Online } \\
\text { Courses (MOOCs) } \\
\text { - Web-based communication } \\
\text { platforms / instant messaging (e.g., } \\
\text { email or Facebook Messenger) }\end{array}$ \\
\hline $\begin{array}{l}\text { Application- } \\
\text { based mobile } \\
\text { learning }\end{array}$ & $\begin{array}{l}\text { - Feature phones } \\
\text { - Smart phones }\end{array}$ & $\begin{array}{l}\text { - } \text { As above } \\
\text { - } \text { Educational apps and games } \\
\text { learning groups } \\
\text { - App-based Learning Management } \\
\text { - Systems and MOOCs } \\
\text { - App-based communication } \\
\text { platforms / instant messaging (e.g., } \\
\text { WhatsApp) }\end{array}$ \\
\hline
\end{tabular}

Mobile phones provide an option to support education service delivery in a range of contexts around the world. Widespread access to mobile phones means they can support education service delivery during the COVID-19 pandemic and beyond. This has already begun to occur. In March 2020, there was a 90\% increase in global downloads of educational applications compared to the fourth quarter of 2019 (Sydow, 2020).

Alternatively, in areas where access is not as high, phones could be a good investment that can be used not only for education, but also for cross-sectoral development programming. The cost of phones is lower than other devices (e.g., tablets, laptops, etc.). Phones are extremely transferrable and can be leveraged for other development initiatives including the use of mobile money for cash transfer programmes, e-health programmes, or digital citizenship initiatives.

\subsubsection{The use of phones to support learning during the COVID-19 pandemic}

During the COVID-19 pandemic, mobile phones have already been leveraged to support education programming in many different ways. These examples are current and are yet to be evaluated. Despite this, they provide valuable insights into how phones can be used to support education service delivery.

In Bangladesh, the Bangladesh Rural Advancement Committee (BRAC) has provided remote learning by mobile phone for children in BRAC schools (Chowdhury, et al., 2020). This programme generally targets hard-to-reach children in rural areas and urban slums. Teachers facilitate phone-based classes for groups of approximately 5 children lasting for circa 20 minutes at a time. Approximately 83,000 children in 2,762 schools are receiving classes through this initiative. Content delivered by teachers includes psycho-social support, revision and ongoing curriculum implementation. Also in Bangladesh, a national call centre is being established to provide support to both teachers and students (Government of Bangladesh, 2020). The call centre will connect 
over 450,000 teachers with students. Students can call 3336 to ask questions to a teacher from a specific grade and subject. Teachers become eligible to provide support through this platform by completing an online training course.

A recent survey performed by Uwezo (2020) in Kenya identified WhatsApp as the platform that is most favoured by teachers to reach Kenyan learners during the COVID-19 pandemic-related school closures. Approximately $70 \%$ of schools are using WhatsApp to provide learners with materials and content to support alternative education. Approximately 33\% of teachers also used SMS messaging to send content and / or information to students. However, while the survey highlighted that teachers regularly use WhatsApp, it indicated that just $27 \%$ of students accessed content via WhatsApp. This is attributed to challenges including data and connectivity and access to their parents' phones. This indicates that while Whatsapp can provide teachers with an alternative way to distribute content, this alternative approach does not work for all learners and should be deployed in conjunction with other, more accessible, methods. This may include books, print materials in newspapers and SMS.

In India, the use of mobile applications to support learning has grown dramatically. Use of the BYJU'S learning application expanded by more than 6 million users in March alone (Sangwan, 2020). ${ }^{11}$ The app, which targets students in grades 1-12, mainly focuses on mathematics and science. However, it also provides support for examination preparation across various subjects. Students accessing the application spend an average of 71 minutes per day on the application. BYJU'S significant growth came after it offered students free access to the application, which has traditionally required payment after the first 15 days of usage. Previously, access for K-12 students cost 10,000 Indian Rupees (US\$130) per year. While this is well beyond the means of most hard-to-reach children, BYJU'S has shown willingness to provide free access in times of crisis and may be open to discussions of discounted rates if working with development partners.

\subsubsection{The use of phones to support learning prior to the COVID-19 pandemic}

Evidence of the impact of phone-based education programming - whether in class or at a distance - has been proliferating for some time. Phones can provide students who do not have access to formal schooling. While the examples below are focused on phone-based education, some examples are accessible across multiple devices including tablets and computers. This demonstrates the flexibility of designing applications for these devices.

In Kenya, eLimu supports the provision of literacy education to refugees in Dadaab the third largest refugee camp in the world. ${ }^{12}$ eLimu works with local communities to develop digital storybooks that contain locally relevant stories. In Dadaab, eLimu worked with local communities to identify 20 high-priority local stories. They then

\footnotetext{
${ }^{11}$ For more information on this application see BYJU (n.d.). This information is available at https://byjus.com/.

${ }^{12}$ For more information on this programme see eLimu (n.d.). This information is available at https://e-limu.org/.
} 
recorded refugees narrating these stories in their language (often Somali, but with some resources available in Swahili and English) before illustrators developed digital storybooks (Rich, 2018). These digital storybooks were uploaded onto the eLimu app, along with literacy-building functionality such as letter tracing and spelling activities. While eLimu is accessible from phones, the app was pre-installed onto tablets as part of BRCK's Kio Kit. The Kio Kit includes solar charging to enable it to be deployed in the most hard-to-reach areas. ${ }^{13}$ Outside of this initiative, eLimu also provides learning materials for all students in Kenya. This includes reading support materials and access to previous exam papers for revision. Access to exam papers is available at the cost of 1 Kenyan Shilling (US\$ .01) per day.

Mobile phones have also previously been used to provide literacy education for children in Pakistan. UNESCO's Literacy Promotion through Mobile Phones project used an SMS-based approach to develop the skills of 250 urban children. Over four months, participants in the pilot both sent and received text messages that helped build confidence and competence in basic literacy. The project, which cost less than US\$57 per learner - including the cost of purchasing a mobile phone - demonstrated a significant increase in literacy levels over the four months (Miyazawa, 2009).

\subsubsection{The potential use of mobile phones as part of Pakistan's COVID-19 education response}

In Pakistan, mobile phones are a readily available, flexible, low-cost tool that can be leveraged to provide distance education. Approximately 85 percent of the urban population and 66 percent of the rural population already own mobile phones (see Figure 1). The above examples demonstrate that phones can be used to provide education services to those in the most hard-to-reach areas. This includes students who have never previously attended school (like many in Dadaab) and those who have never previously been enrolled (like those in Bangladesh and India).

However, mobile phones are not a silver bullet. To be most effective, a detailed analysis of the target population must be undertaken before the start of any phone-based initiative. Only by understanding the contextual challenges and opportunities faced by students can mobile phone-based education solutions be deployed efficiently and effectively. For example, many children in remote areas may not have phones or a connection to the internet. Even in cases where families own phones, a child's access may be limited if adults are using the device for other purposes. Projects targeting these children may have to purchase devices and preload devices with relevant content. Alternatively, children who have access to smartphones or more elaborate devices may not be motivated to engage in learning on a feature phone or via SMS. Phone-based education interventions will be most successful when they target population segments with access to appropriate technology.

To facilitate learning in the Pakistan context, any mobile phone-based intervention must be tailored to the local context. This includes ensuring that the applications are adapted to the local language of instruction, cultural context and digital literacy levels. While

\footnotetext{
${ }^{13}$ For more information on the KioKit see BRCK (2020). This information is available at https://www.brck.com/education/.
} 
there is significant mobile-based content available globally which can support the rapid development of a content base to support mobile phone learning, some time and financial resources will need to be expended to ensure these will support learning in Pakistan.

\subsection{Online learning}

This subsection examines how online learning can be used to provide education services to hard-to-reach children in Pakistan. The subsection first provides an overview of how online learning can be used to support distance education generally. It then provides two case studies: one in Nepal and one that is applicable on a global scale. After these examples, the subsection provides suggestions on how online learning can be used to support Pakistan's COVID-19 education response.

\subsubsection{Using online platforms to support learning}

The Global Partnership for Education (GPE) identifies online learning as one of four options that can facilitate learning during school closures due to the COVID-19 crisis (Burns, 2020). UNESCO (2020) identifies the following types of online learning platforms:

- digital learning management systems

- systems built for use on basic mobile phones

- systems with strong offline functionality

- Massive Open Online Courses (MOOCs)

- self-directed learning content

- mobile reading applications

- collaboration platforms that support live-video communication

- tools for teachers to create digital learning content

- external repositories of distance learning solutions

Online learning is also grouped into two broad categories - asynchronous learning and synchronous learning.

- Asynchronous learning allows learners to access the same material at different places and different points of times. Learners can decide how fast to progress through materials. An example of asynchronous programmes is using the same e-learning website at different points and times.

- Synchronous learning happens in real-time. Online live classroom teaching and video conferencing are some manifestations of synchronous learning.

Both types of online learning provide distinct opportunities and pose unique challenges for learners. In asynchronous learning, for example, learners may feel isolated or may not receive real-time support which can result in reduced motivation. Meanwhile, synchronous learning requires advanced self-management skills, internet connectivity and access to a suitable device. 


\subsubsection{The use of online learning to support learners for Hard-to-reach children}

The Open Learning Exchanges' (OLE) E-Pustakalaya programme offers a free and open digital library. The library contains a collection of over 6,000 books, audiobooks, and reference materials. The programme provides children with free and open access to age-appropriate reading materials while also encouraging them to learn through independent research and inquiry. Students and teachers can freely use these materials both in class and after class.

In addition to the E-Pustakalaya programme, OLE designs and develops educational content, which is distributed for free. OLE has also worked with teachers to bring about change in the classroom. For example, OLE supports teachers with little or no prior experience of technology to gain the skills necessary to use technology to improve learning outcomes. OLE also provides customised technological hardware to under-resourced schools in rural Nepal.

The World Bank, the Center for Education Innovations and GPE identified OLE as one of the most innovative EdTech programmes in South Asia (Wodon, 2015; Trucano, 2017). OLE was also a recipient of an MIT J-WEL grant in K-12 Education Innovation. Wodon (2015) reported that OLE successfully delivered technology-supported education programmes in Nepal after the 2015 earthquake.

\subsubsection{Using Khan Academy's online and offline platform as education response to COVID-19 and hard-to-reach children}

Khan Academy is a California-based non-profit organisation that produces educational video tutorials, lessons, and learning tools to help students learn across the world. Khan Academy's educational content is available for free on its website as well as its e-learning app. The material is produced in a multiple languages, including Urdu, and is regularly reviewed and updated. Khan Academy has also launched a number of interventions to increase access to its resources to benefit students from LMICs.

ICTworks (2016) recommends using offline tools to benefit students in countries facing infrastructure challenges. In line with these suggestions, Khan Academy distributes content for offline use. Khan Academy also allows and supports various organisations around the world to disseminate its content available offline. Kolibri, for example, has made Khan Academy content available offline in a number of LMICs. Kolibri offers tools for self-paced and collaborative learning. Studies have shown that the customisation and adaptation of both online and offline learning can prove useful. For example, a research study on digital accessibility and digital literacy among teachers in Punjab suggests that digital learning materials can work effectively when delivered through synchronous and asynchronous learning platforms (DevTrio Consultants, 2019). The customisation and combination of online and offline content offers an opportunity to increase access to curriculum-aligned education and to improve existing school infrastructure to cater to future learning needs. 


\subsubsection{The potential use of online learning as part of Pakistan's COVID-19 education response}

There is widespread hope and enthusiasm for online learning. For example, the World Education Forum (Li \& Lalani, 2020) advises that online learning can be extremely effective. Moreover, Zahra-Malik (2020) noted that online apps and platforms in Pakistan have witnessed an exponential rise in subscriptions since schools closed. For example, the Taleemabad app has seen a 660\% rise and the Muse SABAQ a 200\% rise. This shows the potential for online learning as an alternative to formal schooling during closures. Banerjee et al. (2016) contend that to benefit students where there are infrastructure challenges, the combination of online and offline versions is greatly beneficial. In short, policymakers should note the effectiveness of blending both online and offline learning to help maximise the reach of education programmes.

It is important to note, however, that, online learning should be considered as part of a multimodal strategy to reach marginalised learners. Although some countries have high levels of device ownership, these statistics mask the fact that hard-to-reach children lack access to internet-enabled devices. While Figure 1 suggests that there is reasonable smartphone penetration in rural areas of Pakistan, further disaggregation is needed to better understand the potential impact of online learning on the learning outcomes of marginalised groups. Although a household may have access to a smartphone, this does not mean that children in that household can use this device for educational purposes.

Additionally, the ability to learn from digital resources - and the ability to learn independently - appears to be related to socioeconomic status. As such, online learning tools should be deployed in strategic ways that ensure the most marginalised learners are not further disadvantaged by their inability to access online resources (Haßler, 2020). Adaptation of the lessons learned from the EdTech models discussed and proposed above could ensure that the benefits of online learning are multiplied and the most marginalised groups are given the top priority. 


\section{Recommendations}

Pakistan should adopt a multimodal COVID-19 education response plan that uses various types of technology to reach the greatest number of learners. This response should use existing resources and consider what technologies marginalised populations can access. Based on this overarching proposal to deliver a multimodal approach, we present the following recommendations.

\section{Recommendation 1: Low-tech interventions need to be considered. The first priority should be to ensure that children can access printed learning materials from home. While many different technological modalities are available to support distance learning, the most disadvantaged children will only have limited access to technology. Figure 1 depicts modality coverage and it shows that only $25 \%$ of the population has an internet connection. Therefore, low-tech interventions need to be considered. The first priority should be to ensure that children have access to existing printed learning materials that they can use from home.}

Recommendation 2: Educational television, mobile phone-learning and online learning can all be leveraged to support distance learning in Pakistan. However, these should be used in combination to heighten the chance hard-to-reach children in Pakistan can access education through at least one of these modalities.

Recommendation 3: Television should be used to support learning outside of the classroom both during and after the current pandemic. The high rate of television ownership across Pakistan suggests that this mode of education can support students in remote areas and urban slums. Moreover, the temporarily out-of-school children due to COVID-19 can continue to access educational television in their homes after schools reopen. Education providers should draw on existing, localised resources such as content from Teleschool, Taleem Ghar and (where possible) Khul Ja Sim Sim or Sim Sim Hamara.

\section{Recommendation 4: Mobile phones should be used to support learning both in} and outside of the classroom. In Pakistan, mobile phones represent a low-cost tool that children in urban slums, students in remote areas and out-of-school children can access. Teachers can use phone calls, SMS messaging and WhatsApp to help students build foundational skills and offer psycho-social support given the high rate of mobile ownership in Pakistan. A telephone hotline could also be set up to address the concerns of teachers, students and parents. If students have access to smartphones, education providers should offer a curated list of applications with curriculum-aligned content. If mobile phones are used to deliver content then these interventions should be designed to ensure that hard-to-reach students will be able to access the content despite limited ability to purchase data or access to internet connectivity. This might involve prioritising basic and feature phones. In some cases, supplying users with phones preloaded with education applications may be necessary.

Recommendation 5: Interactive radio instruction, and other forms of radio-based instruction, should not be a priority in the immediate response. While educators have used interactive radio instruction to improve learning outcomes at scale, interactive radio instruction broadcasts will have limited reach in Pakistan due to the 
low rates of radio ownership in rural and urban areas illustrated in Figure 1. Even if children could access radio broadcasts, evidence from previous crises suggests learning outcomes remain heavily dependent on ongoing adult supervision. While radio instruction should not be considered in the short term, in the medium- to long-term it could be used to reach out-of-school children.

Recommendation 6: Educational resources need to be adapted to the local context and the needs of marginalised students regardless of the mode of delivery. Content should reflect the language, culture and competencies of target groups. In practice, educators may need to add subtitles in local dialects to television episodes. Alternatively, education providers may need to provide additional scaffolding to help out-of-school children navigate unfamiliar subjects.

Recommendation 7: Regardless of the modality adopted, programme designers should attempt to reuse and re-deploy content wherever possible. This may include replaying the same content on various occasions (e.g., multiple screenings of the same television shows) or using content designed for one modality on another (e.g., uploading content designed for television to YouTube). This creates economies of scale and will help ensure that multiple students with access to different modalities will be able to engage with content.

Recommendation 8: Adequate training and supporting materials should be made available to teachers and caregivers to ensure they can effectively play their role in delivering remote education services. The exact nature of the training / support should be aligned with the modality being leveraged or programme being deployed. A robust communication plan should be developed to ensure students, teachers and parents are aware of the tools at their disposal to support learning continuity.

Recommendation 9: The federal ministry and provincial departments of education should ensure that their COVID-19 education plans are aligned and well-coordinated to effectively reach the students most in need. DFID should work with the government to establish an inter-departmental working group to facilitate the design and roll-out of the COVID-19 response.

Recommendation 10: As with more general education programming, any interventions developed to support COVID-19 should include a robust and agile monitoring, evaluation and research system. The collection, analysis and evaluation of disaggregated and stratified data will assist in quickly learning and adjusting any distance-learning approach to ensure it meets the needs of students. 


\section{References}

Adam, T., Kaye, T., \& Haßler, B. (2020). The Maldives and Sri Lanka: Question \& Answer Session (EdTech Hub Helpdesk Response No. 18).

https://doi.org/10.5281/zenodo.3885817

Ahmad, I., Ur Rehman, K., Ali, A., Khan, I., \& Khan, F. A. (2014). Critical Analysis of the Problems of Education in Pakistan: Possible Solutions. International Journal of Evaluation and Research in Education (IJERE), 3(2), 79-84.

https://doi.org/10.11591/ijere.v3i2.1805

Asad, S., Habib, M., Karachiwalla, N., Kosec, K., Leaver, C., \& Ur Rehman, A. (2020, February 10). Improving teacher accountability in Pakistan's rural schools. International Growth Centre.

https://www.theigc.org/blog/improving-teacher-accountability-in-pakistans-rural-scho ols/

ASER Pakistan. (2019). Annual Status of Education Report.

Basic Education Coalition. (2020). Pivot Stories: BEC Members Continue to Meet New Learner Needs during COVID-19. Basic Education Coalition.

Batada, A., Banerjee, S., Subramanian, M., Banerjee, S., \& Subramanian, M. (2016). Opening New Doors: Community Engagement in India. In The Sesame Effect: The Global Impact of the Longest Street in the World (pp. 207-229). Routledge. https://doi.org/10.4324/9781315751399-22

BBC. (2012, June 5). US pulls Pakistan Sesame Street aid. https://www.bbc.com/news/world-asia-18329054

Boone, J. (2012, June 5). US pulls funding from Pakistan's Sesame Street. The Guardian. https://www.theguardian.com/world/2012/jun/05/pakistan-sesame-street-funding-wi thdrawn

Borzekowski, D. (2015). Sesame street in the tea estates: A multi-media intervention to improve sanitation and hygiene among Bangladesh's most vulnerable youth. Annals of Global Health, 81, 107-108. https://doi.org/10.1016/j.aogh.2015.02.748

Borzekowski, D. L. G., Singpurwalla, D., Mehrotra, D., \& Howard, D. (2019). The impact of Galli Galli Sim Sim on Indian preschoolers. Journal of Applied Developmental Psychology, 64. https://doi.org/10.1016/j.appdev.2019.101054

Borzekowski, D., Lando, A. L., Olsen, S., \& Giffen, L. (2019). The Impact of an Educational Media Intervention to Support Children's Early Learning in Rwanda. International Journal of Early Childhood. https://doi.org/10.1007/s13158-019-00237-4 
BRCK. (2020). BRCK | KioKit. https://www.brck.com/education/

Bricklin, J. (2012, June 6). Killing 'Sesame Street' In Pakistan. Forbes.

https://www.forbes.com/sites/juliabricklin/2012/06/06/killing-sesame-street-in-pakist an/

Burns, M. (2020). School, interrupted: 4 options for distance education to continue teaching during COVID-19. Global Partnership for Education.

https://www.globalpartnership.org/blog/school-interrupted-4-options-distance-educa tion-continue-teaching-during-covid-19

Carlson, S. (2013). Using Technology to Deliver Educational Services to Children and Youth in Environments Affected by Crisis and/or Conflict. USAID.

CGTN. (2020, February 12). Chinese education authorities to broadcast lessons on television. https://www.youtube.com/watch?v=5E2RQIZCLjs

Chowdhury, Z., Islam, R., \& Saltmarsh, S.-J. (2020). How BRAC is supporting Bangladesh to continue education in a pandemic.

http://blog.brac.net/how-bangladesh-is-continuing-education-in-a-pandemic/

DevTrio Consultants. (2019). Research into Digital Accessibility and Literacy among School Teachers in Punjab: Research Report. British Council. https://www.britishcouncil.pk/sites/default/files/dal compressed 22 august 2019.pd $\underline{f}$

eLimu. (n.d.). ELimu | Home. Retrieved 11 June 2020, from https://e-limu.org/

Fasih, T., Baron, J., \& Geven, K. M. (2019). Pakistan: Learning Poverty Brief. EduAnalytics. http://pubdocs.worldbank.org/en/214101571223451727/SAS-SACPK-PAK-LPBRIEF.pdf

Fernald, L., Alderman, H., Behrman, J., O'Gara, C., Yousafzai, A., Cabral de Mello, M., Hidrobo, M., Ulkuer, N., Ertem, I., \& Iltus, S. (2011). Strategies for reducing inequalities and improving developmental outcomes for young children in low-income and middle-income countries. Lancet, 378, 1339-1353.

https://doi.org/10.1016/S0140-6736(11)60889-1

Government of Bangladesh. (2020a). COVID-19 Response and Recovery Plan.

https://mopme.gov.bd/sites/default/files/files/mopme.portal.gov.bd/notices/c56bd6a 7 75e3 4435 bad9 efff2f714192/COVID\%2019\%20Response\%20and\%20Recovery\%2 OPlan Govt.pdf

Government of Bangladesh. (2020b). Compendium of Social Protection Research in Bangladesh. The General Economics Division (GED), Bangladesh Planning Commission. 
http://socialprotection.gov.bd/wp-content/uploads/2020/03/Compendium-of-Social-P rotection-Research-in-Bangladesh.pdf

Government of Pakistan. (n.d.). Ministry of Federal Education and Professional Training. Retrieved 11 August 2020, from http://www.mofept.gov.pk/Detail/ODJIMmMyYTktN2QxYy00Y2YOLWIwYjYtZmYXMDNI YmRkNmQw

Government of Pakistan. (2018). Pakistan Education Statistics (2016-17). http://library.aepam.edu.pk/Books/Pakistan\%20Education\%20Statistics\%202016-17.p df

Government of Pakistan. (2020). Pakistan Social \& Living Standards Measurement Survey (2018-19). Pakistan Bureau of Statistics.

Government of Sindh. (2019). School Education Sector Plan and Roadmap for Sindh. https://www.globalpartnership.org/sites/default/files/document/file/2020-19-Pakista n-Sindh-ESP.pdf

Government of the Punjab. (2019). Punjab Education Sector Plan (2019-2024).

https://planipolis.iiep.unesco.org/sites/planipolis/files/ressources/pakistan-punjab-es p.pdf

Government of the Punjab. (2020). Taleem Ghar. https://taleemghar.punjab.gov.pk/ Hallgarten, J. (2020). Evidence on efforts to mitigate the negative educational impact of past disease outbreaks. https://opendocs.ids.ac.uk/opendocs/handle/20.500.12413/15202

Hares, S., \& Mundy, K. (2020). Equity-Focused Approaches to Learning Loss during COVID-19.

https://www.cgdev.org/blog/equity-focused-approaches-learning-loss-during-covid-1 $\underline{9}$

Haßler, B., Khalayleh, A., \& McBurnie, C. (2020). A five-part education response to the COVID-19 pandemic (EdTech Hub Helpdesk Response No. 5). https://doi.org/10.5281/zenodo.3756012

Hina, K. (2017). The USAID Pre-Service Teacher Education Program and Teacher Professionalization in Pakistan. Cambridge Scholars Publishing. https://www.cambridgescholars.com/download/sample/63684

Ho, J., \& Thukral, H. (2009). Tuned in to student success: Assessing the impact of interactive radio instruction for the hardest-to-reach. Education Development Center. http://citeseerx.ist.psu.edu/viewdoc/download?doi=10.1.1.507.3541\&rep=rep1\&type $=\mathrm{pdf}$ 
Human Rights Watch. (2018). 'Shall I feed my daughter, or educate her?': Barriers to girls' education in Pakistan. Human Rights Watch.

ICTworks. (2016). What is the Matthew Effect on Khan Academy in India? https://www.ictworks.org/what-is-the-matthew-effect-on-khan-academy-in-india/

Iqbal, N. (2020, August 11). EDUCATION-PAKISTAN: ALIF Spells Open Sesame For Pre-schoolers | Inter Press Service. Inter Press Service News Agency. http://www.ipsnews.net/2000/04/education-pakistan-alif-spells-open-sesame-for-preschoolers/

Jeffrey, R., Oberlander, J., MacDonald, S., \& Bhatti, F. (2016). Digital Citizenship in Pakistan. British Council. https://www.britishcouncil.pk/sites/default/files/digital citizenship in pakistan.pdf

Kaliyadan, R. (2012, April 14). Mediamarx: Voice to the Voiceless. Kheda Communication Project. http://mediamarx.blogspot.com/2012/04/kheda-communication-project.html

Kheda Communication Project. (n.d.). Retrieved 11 June 2020, from http://ecoursesonline.iasri.res.in/mod/page/view.php?id=116100

Kolucki, B., \& Lemish, D. (2011). Communicating with children: Principles and practices to nurture, inspire, excite, educate and heal. UNICEF.

Lamba, K., \& Reimers, F. (2020). Sierra Leone and Liberia: Rising Academy Network on air. https://oecdedutoday.com/wp-content/uploads/2020/05/Sierra-Leone-Liberia-RisingAcademy-Network.pdf

Lee, H. J. (2009). Sisimpur's reach and educational impact: Evidence from a national longitudinal survey of a Sesame Street project in Bangladesh. Sesame Workshop.

Li, C., \& Lalani, F. (2020). The COVID-19 pandemic has changed education forever. This is how. World Economic Forum.

https://www.weforum.org/agenda/2020/04/coronavirus-education-global-covid19-onl ine-digital-learning/

Mares, M., \& Pan, Z. (2013). Effects of Sesame Street: A meta-analysis of children's learning in 15 countries. Journal of Applied Developmental Psychology, 34, 140-151. https://doi.org/10.1016/j.appdev.2013.01.001

McAleavy, T., \& Gorgen, K. (2020). What does the research suggest is best practice in pedagogy for remote teaching?

McBurnie, C. (2020). The use of virtual learning environments and learning management systems during the COVID-19 pandemic (EdTech Hub Helpdesk Request No. 7). https://doi.org/10.5281/zenodo.3805843 
McGeown, J., Boisseau, S., \& Bohan-Jacquot, S. (2020). Guidance Note 2: Teacher Resources. Humanity and Inclusion.

https://inee.org/system/files/resources/IE\%20Series\%20of\%20BRIEFS\%20to\%20supp ort\%20COVID\%2019\%20\%20\%23\%202\%20Teachers\%20External\%20ENGLISH.pdf

McIntyre, N., \& Watson, J. (2020). Rapid Evidence Review: TV. EdTech Hub.

Miller, T., Jervis, V., Burns, J., Wongsaroj, S., \& Hogg, T. (2015). Potential benefits from sub-700 MHz spectrum in Pakistan. GSMA.

Ministry of Education and Federal Training (Pakistan). (2009). National Education Policy. http://itacec.org/document/2015/7/National Education Policy 2009.pdf

Ministry of Education and Federal Training (Pakistan). (2020). National Education Response and Resilience Plan for COVID-19.

http://mofept.gov.pk/Sitelmage/Misc/files/0 \%20NERRP\%20COVID-19\%20MoFEPT\%2 04\%20May\%202020\%20Ver\%2001.pdf

Ministry of Federal Education and Professional Training (Pakistan). (2018). National Education Policy Framework.

http://mofept.gov.pk/Sitelmage/Policy/National\%20Eductaion\%20Policy\%20Framewo rk\%202018\%20Final.pdf

Ministry of IT \& Telecom (Pakistan). (2018). Digital Pakistan Policy. https://www.moitt.gov.pk/Sitelmage/Misc/files/DIGITAL\%20PAKISTAN\%20POLICY.pdf

Miyazawa, I. (2009). Literacy Promotion through Mobile Phones. UNESCO. http://www.unesco.org.pk/education/documents/Project\%20Brief\%20Paper ICT.pdf

Mohiuddin, S. (2009, March 22). Urdu version of Sesame Street from April. The News International.

https://www.thenews.com.pk/archive/print/167150-urdu-version-of-sesame-street-fr om-april

Moss, C. (2020, January 22). 18 large-scale EdTech initiatives on our radar in 2020. The EdTech Hub.

https://edtechhub.org/2020/01/22/18-large-scale-edtech-initiatives-on-our-radar-in-2 $\underline{020 /}$

Munkhzul, A. (2020, March 12). Mongolia leads in organizing TV classes for children. Montsame (Mongolia). https://montsame.mn/en/read/218635

National Institute of Population Studies. (2019). Pakistan Demographic and Health Survey 2017-18. https://dhsprogram.com/pubs/pdf/FR354/FR354.pdf 
Naz, S., Memon, A., ul Haque, M., Nadeem, U., Jamal, G., \& Khan, A. (2016). Pakistan District Education Rankings.

https://d3n8a8pro7vhmx.cloudfront.net/alifailaan/pages/537/attachments/original/1 474368820/Pakistan District Education Rankings 2016 Full Report.pdf?1474368820

Okeleke, K. (2019). The Power of Mobile to Accelerate Digital Transformation in Pakistan. GSMA.

https://www.gsma.com/mobilefordevelopment/wp-content/uploads/2020/06/The-Po wer-of-Mobile-to-Accelerate-Digital-Transformation-in-Pakistan-2019.pdf

OLE Nepal. (2020). E-Pustakalaya | Home. https://www.pustakalaya.org/en/?lang=en

Pakistan Telecommunications Authority. (2019a). PTA Annual Report. https://www.pta.gov.pk/assets/media/pta ann rep 2019 27032020.pdf

Pakistan Telecommunications Authority. (2019b). Telecom Indicators. https://www.pta.gov.pk/en/telecom-indicators

Pasha, H. (2018). Growth and inequality in Pakistan: Agenda for reforms.

Plan International. (2015). Ebola: Beyond the health emergency. Plan International. https://www.plan.ie/wp-content/uploads/2015/03/GLO-Ebola-Final-IO-Eng-Feb15.pdf

Qadir, M. J., \& Hameed, A. (2018). A Study of the Usefulness of Punjab IT Labs Project in Schools of Punjab, Pakistan as Perceived by Students. Journal of Education Research, 21(2).

Rich, S. (2020). Teaching literacy to youth in Dadaab. ELimu. https://e-limu.org/teaching-literacy-youth-dadaab/

Richmond, S. (2020). Repurposing Established Radio and Audio Series to Address the COVID-19 Educational Crises (p. 9). Education Development Center. https://www.edc.org/sites/default/files/Repurposing-Established-Radio-Audio-Series. pdf

Sangwan, S. (2020). Coronavirus: Edtech unicorn BYJU'S free offer sees $150 \%$ jump in new students.

https://yourstory.com/2020/04/edtech-unicorn-byjus-students-free-access-coronavir $\underline{\text { uS }}$

Schwab, K. (2019). The Global Competitiveness Report. World Economic Forum.

Sesame Workshop. (2020). Sisimpur | Sesame Workshop. https://www.sesameworkshop.org/what-we-do/shows/sisimpur

Sydow, L. (2020). Mobile Minute: Global Classrooms Rely on Education Apps As Remote Learning Accelerates. App Annie. 
https://www.appannie.com/en/insights/mobile-minute/education-apps-grow-remotelearning-coronavirus/

Trucano, M. (2017). 20 innovative edtech projects from around the world. World Bank Blogs.

https://blogs.worldbank.org/edutech/20-innovative-edtech-projects-around-world

Turner, A. (2020). 1 Billion More Phones Than People In The World!

https://www.bankmycell.com/blog/how-many-phones-are-in-the-world

Ubongo. (2020). Results_Ubongo Learning. https://www.ubongo.org/results/

UNESCO. (2020). Distance learning solutions.

https://en.unesco.org/covid19/educationresponse/solutions

UNESCO, UNICEF, World Bank, \& World Food Programme. (2020). Framework for reopening schools.

https://unesdoc.unesco.org/ark:/48223/pf0000373348/PDF/373348eng.pdf.multi

UNICEF. (2020). Education: Giving Every Child the Right to Education.

https://www.unicef.org/pakistan/education

USAID. (2020). Delivering Distance Education in Emergencies: A Review of Evidence and Best Practice.

Watson, Joe. (2020, March 31). Learning through television in low-income contexts: Mitigating the impact of coronavirus (COVID-19). The EdTech Hub.

https://edtechhub.org/2020/03/31/learning-through-television-in-low-income-context s-mitigating-the-impact-of-covid-19/

Watson, Joseph. (2020). The relationship between educational television and mathematics capability in Tanzania [Thesis, University of Cambridge].

https://doi.org/10.17863/CAM.54714

Wodon, Q. (2015a). Supporting education in Nepal: Technology that improves teaching and student learning. Rotary International.

https://blog.rotary.org/2015/08/25/supporting-education-in-nepal/

Wodon, Q. (2015b). Technology in the classroom: Learning from OLE Nepal. Global Partnership for Education.

https://www.globalpartnership.org/blog/technology-classroom-learning-ole-nepal

World Bank. (2005). Improving Educational Quality through Interactive Radio Instruction. http://documents.worldbank.org/curated/en/288791468035958279/pdf/357420AFRH D0521lkit1 nov10501PUBLIC1.pdf 
World Bank. (2018). Government expenditure on education, total (\% of GDP)—South Asia, Pakistan, Afghanistan, Bangladesh, Bhutan, India, Maldives, Nepal, Sri Lanka | Data. https://data.worldbank.org/indicator/SE.XPD.TOTL.GD.ZS?end=2018\&locations=8S-PK -AF-BD-BT-IN-MV-NP-LK\&name desc=false\&start=1971\&view=chart

Zahra-Malik, M. (2020, July 14). The coronavirus effect on Pakistan's digital divide. BBC Worklife.

https://www.bbc.com/worklife/article/20200713-the-coronavirus-effect-on-pakistansdigital-divide 